\title{
Evaluation of Coastal Sediment Budget on East Coast Maeongbang Beach by Wave Changes
}

\author{
Gweon-Su Kim ${ }^{\circledR}$, Ha-Sang Ryu ${ }^{*}$ and Sang-Hoon Kim ${ }^{\star *}$ \\ *Port \& Coastal Development Institute, SEIL Engineering Co., Ltd., Seoul, Korea \\ 파랑 변화에 따른 동해안 맹방 해수욕장 연안 표사수지 파악

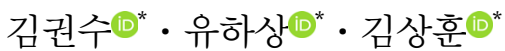 \\ "(주)세일종합기술공사 항만 및 해안개발 기술연구소
}

KEY WORDS: Sediment budget 표사, Delft3d model Delft3d 모델, Wave change 파랑 변화, Input reduction tool 입력 감소 기법, NOAA NCEP NOAA 파랑 자료

\begin{abstract}
Numerical simulation of the sediment by the Delft3d model was conducted to examine the changes in the sediment budget transport caused by long-term wave changes at the Maengbang beach. Representative waves were generated with input reduction tools using NOAA NCEP wave data for about 40 years, i.e., from January 1979 to May 2019. To determine the adequacy of the model, wave and depth changes were compared and verified using wave and depth data observed for about 23 months beginning in March 2017. As a result of the error analysis, the bias was 0.05 and the root mean square error was 0.23 , which indicated that the numerical wave results were satisfactory. Also, the observed change in depth and numerical result were similar. In addition, to examine the effect due to long-term changes in the waves, the NOAA wave data classified into each of the representative wave grades, and then the annual trend of the representative wave was analyzed. After deciding the weight of each wave class considering the changed wave environment in 2100, the amounts of sedimentation, deposition, and the sediment transport budget were reviewed for the same period. The results indicated that the sedimentation pattern did not change significantly compared to the current state, and the amount of the local sediment budget shown in the present state was slightly less. And there has been a local increase in the number of sediment budget transport, but there is no significant difference in the net and amount of sediment movements.
\end{abstract}

\section{1. 서 론}

우리나라 연안은 하천 및 연안의 유사와 표사의 이동 불균형 으로 인해 침식 및 퇴적 변화가 발생하고 있다. 특히 동해안은 파랑 특성의 변화와 하천에서의 모래 공급 감소와 해사채취, 항 만 및 방파제 등의 인공 구조물 건설에 따른 모래의 이동 양상 변화에 의해 연안 침식이 크게 발생하고 있다. 이러한 연안 재 해는 장기간의 파랑 및 기후의 변화를 반영하여 연안 표사수지 를 평가하고, 이에 따른 명확한 연안관리체계를 수립함으로써 해결될 수 있으리라 사료된다.

본 연구에서는 파랑에 의한 모래의 이동 양상 변화를 검토하 기 위해, 해양수산부 연안침식현황 자료(Ministry of Oceans and Fisheries, 2019)에서 2016년부터 “심각" 판정을 받은 맹방해수욕 장에 대하여 퇴적물 이동 실험을 수행하고 표사 이동량을 산정 하였다. 과거 파랑에 의한 퇴적물 이동 실험은 50 년 빈도, 평상
파 또는 계절파(Kim et al, 2018)라는 단일 파랑 조건에 대해 수 치모의가 수행되어 왔다. 또는 실시간 파랑 조건을 이용하여 파 고와 주기, 파향 조건을 그대로 입력하여 5 분, 10 분 혹은 그 이 상의 간격으로 해수유동과 파랑을 연계(Coupling)하여 수치모의 를 수행하고 있다. 단일 파랑 조건의 경우 수치모의에 따른 계 산 소요시간이 획기적으로 줄어드는 장점이 있고, 50 년 빈도 파 랑 조건의 경우 태풍 및 고파랑에 의한 퇴적물 이동을 모의할 수는 있다. 그러나 과대한 연간 침 - 퇴적량이 산정될 수 있고, 평상파의 경우 이와 반대로 고파랑에 의한 침·퇴적량을 과소 평가할 수 있는 것으로 판단된다.

또한 계절파의 경우 계절별 파랑의 영향을 고려할 수 있으나, 이벤트성 파랑에 의한 영향보다는 일반풍에 의한 영향이 상대 적으로 크게 나타날 가능성이 높으므로(Kim and Lee, 2015) 다 양한 파고와 주기, 파향에 대한 분석이 이뤄져야 할 것으로 판 단된다. 그리고 실시간 파랑 조건을 이용하여 파랑을 계산하고

Received 6 November 2019, revised 5 December 2019, accepted 13 December 2019

Corresponding author Gweon-Su Kim: +82-70-8622-7985, kimknsu@hanmail.net ORCID: http://orcid.org/0000-0003-0293-2832

(C) 2019, The Korean Society of Ocean Engineers

This is an open access article distributed under the terms of the creative commons attribution non-commercial license (http://creativecommons.org/licenses/by-nc/3.0) which permits unrestricted non-commercial use, distribution, and reproduction in any medium, provided the original work is properly cited. 
해수유동과 연계하여 퇴적물 이동을 모의할 경우, 5 분, 10 분 등 파랑 계산 간격에 따른 침·퇴적량의 민감도를 계산하여야 하 며, 상당히 발달된 현대 기술에도 불구하고 계산 소요 시간은 막대하게 늘어날 것으로 판단된다. 따라서 실시간 파랑 조건을 이용한 퇴적물 이동 수치실험의 경우 향후 파고와 주기, 파향 등의 변화를 대변한 시나리오를 작성하는 것은 현실적으로 불 가능하다 할 수 있다.

본 연구에서는 단일 파랑 혹은 실시간 파랑 등에 대한 파랑 조건이 아닌, 전체 파랑 조건을 대변할 수 있는 대표 파랑을 생 성하고, 각각의 대표 파랑에 대해 퇴적물 이동 실험을 수행하여 최종 침-퇴적 결과를 도출하였다. 이를 위해 1979년 1월부터 2019년 5월까지 약 40년에 대한 NOAA(National Oceanic and Atmospheric Administration)의 WaveWatchIII 파랑 자료(NOAA / National Weather Service, 2019)를 수집하여, 입력 감소 기법 (Input reduction tool)(Deltares, 2017)을 이용해 62개의 대표 파랑 을 생성하였다. 그리고 모델의 적정성을 판단하기 위해 2017년 3 월부터 약 23 개월간 관측된 파랑 및 수심자료를 이용하여 파 랑변화와 수심 변화를 비교 검증하였다.

또한 장기간의 파랑 변화에 의한 연안표사 수지 검토를 위해, 전술한 약 40년에 대한 $\mathrm{NOAA}$ 의 파랑자료를 검토하여 각 대표 파랑별 등급으로 구분한 후, 대표 파랑의 연간추이를 분석하였 다. 그리고 2100 년 시점의 변화된 파랑 환경을 고려하여 각 파 랑 등급의 가중치를 결정한 후, 전술한 관측 자료와 동일 기간 에 대해 침·퇴적 및 표사 이동량을 검토하였다.

\section{2. 대표 파랑 분석}

연구 대상 영역은 강원도 삼척항으로부터 남측으로 약 $4 \mathrm{~km}$
거리에 있는 개방형 해안으로, 북측에 한재밑 해수욕장과 상맹 방 해수욕장, 남측에 하맹방 해수욕장이 있으며 본 연구에서는 전체를 맹방 해수욕장으로 명명하도록 한다(Fig. 1). 마읍천 하 류의 덕봉산에 인접하여 남측에 덕산 해수욕장이 위치하고 있 고, 마읍천 하구가 맹방 해수욕장과 덕산 해수욕장 사이에 발달 되어 있으나, 하천으로부터의 유사 공급 경로는 대부분 맹방 해 수욕장으로 흘러드는 형태를 나타내고 있다. 또한 맹방 해수욕 장과 덕산 해수욕장을 잇는 평균 해안선은 북을 기준으로 반시 계 방향으로 약 $45^{\circ}$ 기울어져 있고 해안선을 따라 수심 분포가 이루어져 있다.

파랑 특성을 분석하기 위해 NOAA WaveWatchIII 파랑자료를 수집하였다. 파랑자료는 1979 년부터 최근까지 $0.5^{\circ}$ 해상도에 대 해, 3 시간 간격의 파고와 주기, 파향 등의 정보로 이루어져 있 다. 본 연구에서는 맹방 해변으로부터 가장 근접하여 약 $26 \mathrm{~km}$

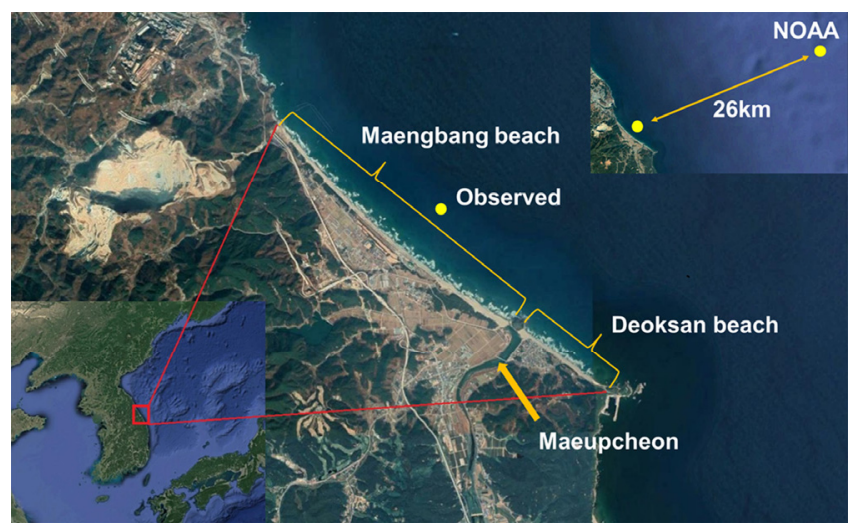

Fig. 1 Overview of target area and observation point (Maengbang beach, Gangwon, Korea)

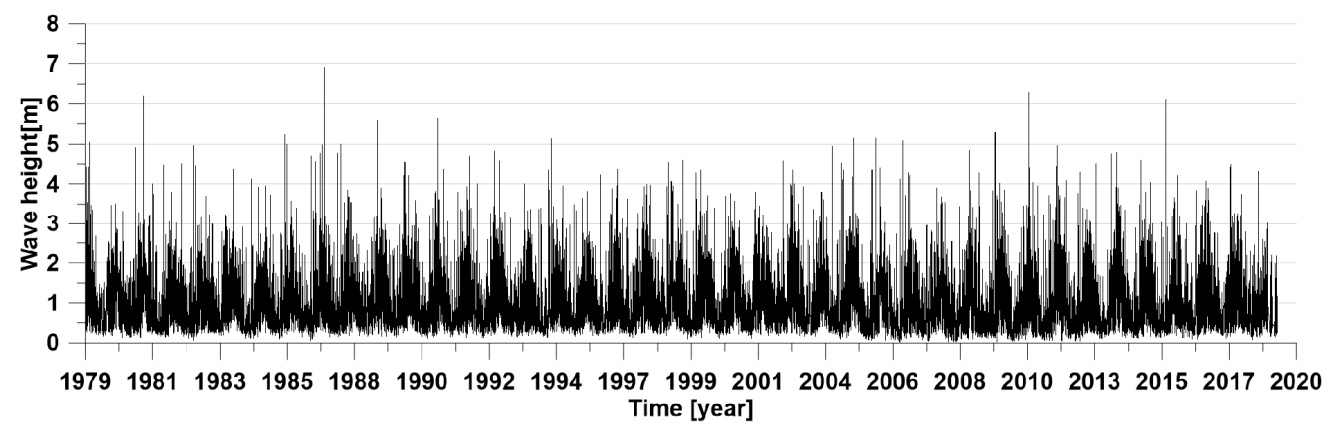

(a) Time series of significant wave height

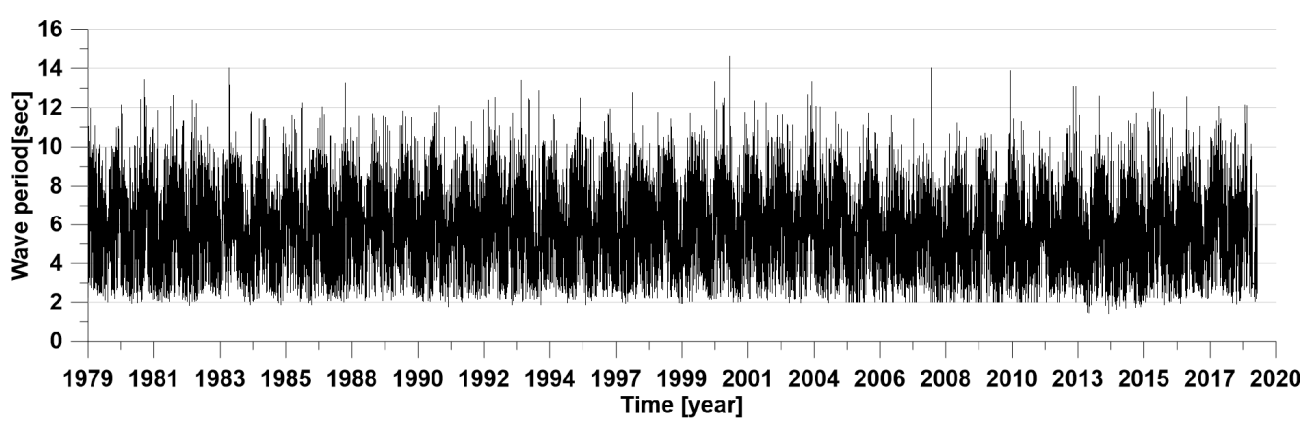

(b) Time series of wave period

Fig. 2 NOAA wave data at Maengbang beach offshore 


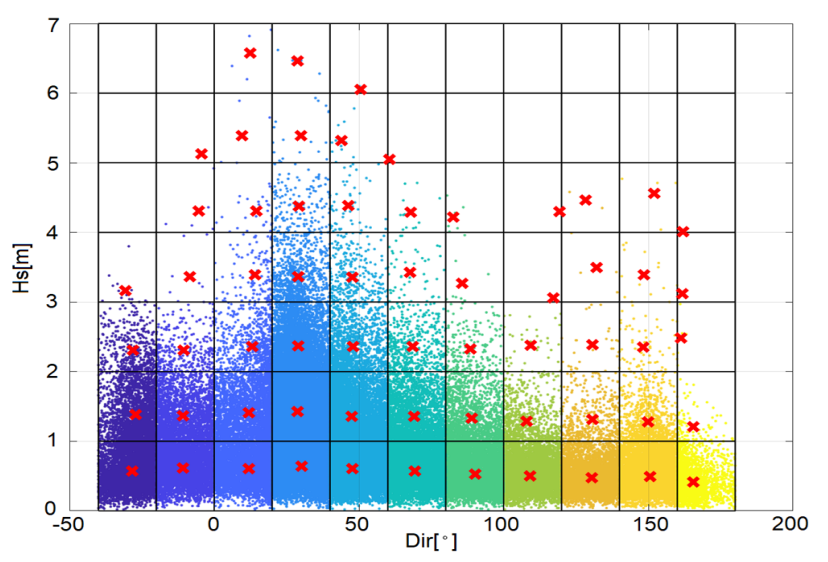

Fig. 3 Analysis of observation data using input reduction tool (The relationship between wave direction and significant wave height)
외해에 위치한 NOAA WaveWatchIII 격자(경도: $129.5^{\circ}$, 위도: $37.5^{\circ}$ )로부터 약 40 년간의 파랑자료를 수집하였고, 이 파랑자료 에 대한 파고와 주기 시계열을 Fig. 2에 도시하였다.

대표 파랑은 입력 감소 기법(Input reduction tool)(Deltares, 2017)을 활용하여 생성하였다. 파고는 $1 \mathrm{~m}$ 고정 간격으로 $0 \mathrm{~m}$ $7 \mathrm{~m}$ 까지 7 등급, 파향은 $-40^{\circ} \sim 180^{\circ}$ 까지 $20^{\circ}$ 간격으로 11 등급을 나눠 분석하였다. 다음에 분석된 파향-파고간의 관계를 Fig. 3 에 도시하였다

분석된 대표 파랑 제원은 모두 62 의 대표 파랑으로 구성되고 (Table 1), 순서는 수집된 파랑 전체 자료(118,083개) 중 각 대표 파랑의 비율에 따르며, Fig. 4에 도시한 바와 같다.

첫 번째 대표 파랑인 파고 $0.61 \mathrm{~m}$, 주기 $6.53 \mathrm{~s}$, 파향 $47.74^{\circ}$ 인 파랑은 전체에서 약 $12 \%$ 를 차지하고 있고, 21 번째 대표 파랑인 경우 전체에서 $1 \%$ 에도 미치지 못하는 결과를 보여주고 있다.

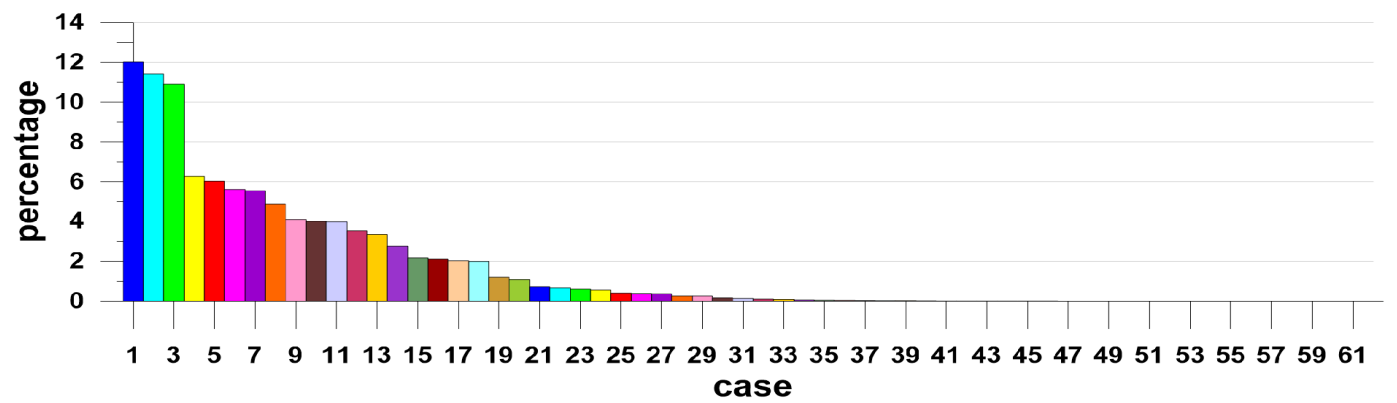

Fig. 4 Representative individual wave data ratio to total wave data

Table 1 Representative wave specifications

\begin{tabular}{|c|c|c|c|c|c|c|c|c|c|}
\hline Order & $H_{s}[\mathrm{~m}]$ & $T_{p}[\mathrm{~s}]$ & $\Theta_{m}[\operatorname{deg}]$ & Count [\%] & Order & $H_{s}[\mathrm{~m}]$ & $T_{p}[\mathrm{~s}]$ & $\Theta_{m}[\mathrm{deg}]$ & Count $[\%]$ \\
\hline 1 & 0.61 & 6.53 & 47.74 & 12.021 & 32 & 3.39 & 9.20 & 14.15 & 0.104 \\
\hline 2 & 0.64 & 6.36 & 30.12 & 11.422 & 33 & 1.21 & 6.19 & 165.64 & 0.087 \\
\hline 3 & 1.43 & 7.72 & 28.80 & 10.905 & 34 & 2.35 & 7.75 & 148.32 & 0.059 \\
\hline 4 & 0.49 & 4.66 & 150.48 & 6.291 & 35 & 4.39 & 10.18 & 46.38 & 0.046 \\
\hline 5 & 0.57 & 5.38 & 69.38 & 6.036 & 36 & 3.43 & 9.07 & 67.76 & 0.042 \\
\hline 6 & 0.53 & 4.81 & 90.21 & 5.634 & 37 & 2.38 & 7.55 & 109.28 & 0.035 \\
\hline 7 & 1.36 & 7.89 & 47.57 & 5.568 & 38 & 4.30 & 9.80 & 14.57 & 0.026 \\
\hline 8 & 0.50 & 4.53 & 109.22 & 4.890 & 39 & 2.39 & 7.57 & 130.62 & 0.024 \\
\hline 9 & 0.57 & 5.17 & -28.36 & 4.083 & 40 & 5.39 & 10.72 & 30.08 & 0.016 \\
\hline 10 & 0.47 & 3.97 & 130.38 & 3.985 & 41 & 3.16 & 8.12 & -30.58 & 0.013 \\
\hline 11 & 0.61 & 5.37 & 12.01 & 3.957 & 42 & 3.39 & 8.70 & 148.46 & 0.013 \\
\hline 12 & 0.61 & 5.01 & -10.89 & 3.527 & 43 & 4.29 & 9.43 & 67.98 & 0.011 \\
\hline 13 & 2.37 & 8.78 & 29.01 & 3.323 & 44 & 5.32 & 10.40 & 43.94 & 0.010 \\
\hline 14 & 1.41 & 7.12 & 11.95 & 2.743 & 45 & 3.27 & 8.51 & 85.56 & 0.008 \\
\hline 15 & 1.36 & 6.83 & 69.07 & 2.164 & 46 & 3.37 & 8.31 & -8.50 & 0.007 \\
\hline 16 & 0.41 & 4.86 & 165.62 & 2.102 & 47 & 4.22 & 9.48 & 82.68 & 0.005 \\
\hline 17 & 1.39 & 6.46 & -27.04 & 2.026 & 48 & 2.48 & 8.61 & 161.21 & 0.004 \\
\hline 18 & 1.36 & 6.54 & -10.78 & 1.995 & 49 & 4.31 & 9.05 & -5.39 & 0.004 \\
\hline 19 & 1.33 & 6.63 & 88.93 & 1.196 & 50 & 4.56 & 9.83 & 151.96 & 0.004 \\
\hline 20 & 2.36 & 8.75 & 48.02 & 1.085 & 51 & 3.50 & 8.33 & 132.06 & 0.004 \\
\hline 21 & 1.28 & 6.34 & 149.99 & 0.712 & 52 & 6.46 & 11.09 & 28.90 & 0.004 \\
\hline 22 & 3.36 & 9.44 & 28.97 & 0.664 & 53 & 6.58 & 11.59 & 12.33 & 0.004 \\
\hline 23 & 1.29 & 6.23 & 107.93 & 0.606 & 54 & 5.39 & 10.34 & 9.53 & 0.004 \\
\hline 24 & 2.36 & 8.39 & 13.20 & 0.562 & 55 & 4.47 & 9.63 & 128.43 & 0.002 \\
\hline 25 & 2.36 & 8.03 & 68.64 & 0.406 & 56 & 6.06 & 11.19 & 50.69 & 0.002 \\
\hline 26 & 2.31 & 7.50 & -28.17 & 0.382 & 57 & 4.01 & 9.77 & 161.89 & 0.001 \\
\hline 27 & 1.31 & 5.79 & 130.60 & 0.372 & 58 & 3.12 & 9.38 & 161.74 & 0.001 \\
\hline 28 & 3.36 & 9.44 & 47.86 & 0.255 & 59 & 4.30 & 9.17 & 119.26 & 0.001 \\
\hline 29 & 2.31 & 7.55 & -10.59 & 0.250 & 60 & 3.06 & 8.50 & 117.08 & 0.001 \\
\hline 30 & 2.33 & 7.80 & 88.48 & 0.163 & 61 & 5.05 & 8.95 & 60.46 & 0.001 \\
\hline 31 & 4.38 & 9.88 & 29.36 & 0.131 & 62 & 5.13 & 9.69 & -4.44 & 0.001 \\
\hline
\end{tabular}




\section{3. 수치모의}

\subsection{Delft3d 모델}

Delft3d 모델은 흐름, 토사이송, 파랑, 수질, 바닥지형 변화와 생태환경의 모의를 수행하는 3차원 수치모형으로 네덜란드의 Delft 수리연구소에서 개발하였다. Delft3d 모델의 패키지는 상 호 접속할 수 있는 다수의 모듈로 구성되어 있으며 수질, 파랑 과 지형변화와 같은 모듈에 대한 동수역학적 기본 자료를 제공 한다. Delft3d-flow의 연직방향 격자는 $\sigma$ 좌표 접근법을 따른다 고 정의하고 조석과 폭풍해일, 성층화되고 밀도가 지배적인 흐 름, 강 흐름 모의, 담수가 만으로 유출되는 유출율, 염의 침투, 열 성층화, 냉각수 취수와 폐수 배출, 용해물질과 오염물의 이 송, 파랑이 지배적인 흐름을 모의할 수 있다.

\subsubsection{Delft3d-wave 모델}

Delft3d-wave 모델(Deltares, 2018b)의 파랑변형 실험은 연안에 서 파랑의 생성과 전파, 비선형 파랑상호작용 및 감쇄 등을 계 산하기 위해 SWAN(Simulationg waved nearshore) 모델을 이용한 다. 파랑작용 평형방정식(Wave action balance equation)을 기본 방적으로 하며, 파향 에너지 스펙트럼의 형태로 파랑 작용을 나 타내고, 2차원 수평공간에 대해 파랑 스펙트럼의 변화를 식 (1) 과 같이 에너지 평형방정식으로 계산한다.

$$
\frac{\partial N}{\partial t}+\frac{\partial c_{x} N}{\partial x}+\frac{\partial c_{y} N}{\partial y}+\frac{\partial c_{\sigma} N}{\partial \sigma}+\frac{\partial c_{\theta} N}{\partial \theta}-\frac{S}{\sigma}=0
$$

여기서, $N$ 은 작용 밀도 스펙트럼, $t$ 는 시간, $x, y$ 는 수평방향 거리, $\sigma$ 는 상대 각주파수, $\theta$ 는 방향, $S$ 는 원천항(Source terms)을 나타낸다. 또한 $c_{x}, c_{y}, c_{\sigma}, c_{\theta}$ 는 각각 $x, y, \sigma, \theta$ 에 대한 파랑의 전파속도를 나타내며, 작용 밀도 스펙트럼 $N(\sigma, \theta)$ 은 에너지 밀 도 스펙트럼 $E(\sigma, \theta)$ 과 $N(\sigma, \theta)=E(\sigma, \theta) / \sigma$ 의 관계를 갖는다.

\subsubsection{Delft3d-flow 모델}

Delft3d-flow 모델(Deltares, 2018a)은 비압축성을 가정한 연속 방정식과 천수(Shallow water)화 및 Boussinessq 근사를 적용한 비압축성 유체에 대해 Navier Stokes 방정식을 계산한다. 조석, 파랑 및 바람 등의 외력 조건에 대해 해안, 강, 하구 등의 수리 현상 및 유사 이동 등을 모의할 수 있으며, 연속 방정식은 다음 과 같이 수심 평균한 편미분방정식으로 표현할 수 있다.

$$
\frac{\partial \eta}{\partial t}+\frac{\partial(d+\eta) u}{\partial x}+\frac{\partial(d+\eta) v}{\partial y}=0
$$

여기서 $\eta$ 는 해수면 높이, $t$ 는 시간, $d$ 는 수심, $u, v$ 는 각각 $x, y$ 방향에 대한 유속을 나타낸다.

수리 현상 및 유사 이동을 모의하기 위해, 비압축성 유체 에 대한 Navier Stokes 방정식에 대해 천수 및 Boussinesq 근 사를 적용한 수평방향 운동량 방정식은 다음과 같이 나타낼 수 있다.

$$
\begin{aligned}
\frac{\partial \eta}{\partial t} & +u \frac{\partial u}{\partial x}+v \frac{\partial u}{\partial y}+g \frac{\partial \eta}{\partial x}-f u \\
& +\frac{\tau_{b x}}{\rho_{w}(d+\eta)}-\frac{F_{x}}{\rho_{w}(d+\eta)}-\nu\left(\frac{\partial^{2} u}{\partial x^{2}}+\frac{\partial^{2} u}{\partial y^{2}}\right)=0 \\
\frac{\partial \eta}{\partial t}+u \frac{\partial v}{\partial x}+v \frac{\partial v}{\partial y}+g \frac{\partial \eta}{\partial y}-f v & \\
& +\frac{\tau_{b y}}{\rho_{w}(d+\eta)}-\frac{F_{y}}{\rho_{w}(d+\eta)}-\nu\left(\frac{\partial^{2} v}{\partial x^{2}}+\frac{\partial^{2} v}{\partial y^{2}}\right)=0
\end{aligned}
$$

여기서 $f$ 는 코리올리스(Coriolis) 파라미터, $g$ 는 중력가속도, $\tau_{b x}$, $\tau_{b y}$ 는 각각 $x, y$ 방향에 대한 해저면 전단응력, $F_{x}, F_{y}$ 는 각각 $x, y$ 방향으로 작용하는 외력, $\rho_{w}$ 는 물의 밀도, $\nu$ 는 물의 점성 계수를 나타낸다. 본 연구에서는 수치모형실험을 위해 수심평 균 2차원 모델을 사용하였다.

Delft3d-morphology 모델은 앞서 계산된 파랑 및 수리 현상에 의해 모래 이송을 계산하여 바닥 저면의 변화를 산출한다. 비점 착성 퇴적물 이동을 모의하기 위해 다음과 같이 소류사와 부유 사로 구분된 Van Rijn(2001) 및 Van Rijn et al.(2003) 경험식을 사용하였다.

$$
\begin{aligned}
& S_{b}=0.006 \rho_{s} w_{s} D_{50}\left(\frac{v_{e f f}^{2}}{(s-1) g D_{50}}\right)^{0.5}\left(\frac{\left(v_{e f f}-v_{c r}\right)^{2}}{(s-1) g D_{50}}\right)^{0.7} \\
& S_{s, w}=f_{\text {susw }} \gamma\left(\frac{U_{o n}^{4}-U_{o f f}^{4}}{U_{o n}^{3}+U_{o f f}^{3}}\right)\left(0.007 \rho_{s} D_{50}\right)\left(\frac{\left(v_{e f f}-v_{c r}\right)^{2}}{(s-1) g D_{50}}\right) \\
& v_{\text {eff }}=\sqrt{v_{R}^{2}+U_{o n}^{2}}
\end{aligned}
$$

여기서, $S_{b}$ 는 소류사의 이송률, $S_{s, w}$ 는 파랑과 관련된 부유사 이송 률, $g$ 는 중력가속도, $f_{s u s w}$ 는 사용자 정의 변수, $\rho_{s}$ 은 퇴적물의 밀 도, $w_{s}$ 은 침강속도, $D_{50}$ 은 중앙입경, $v_{c r}$ 은 이동하기 시작하는 임계 깊이 평균 속도 $(\mathrm{m} / \mathrm{s}), v_{R}$ 은 대수 속도 프로파일을 가정하여 바닥층 속도로부터 계산된 등가 깊이 평균 속도 $(\mathrm{m} / \mathrm{s}), U_{o n}$ 및 $U_{o f f}$ 은 단파 에 의한 바닥층 인근의 고주파 궤도 속도 $(\mathrm{m} / \mathrm{s})$ 를 나타낸다.

\section{2 모델 수립}

수치실험 시 수치모델의 영역은 동서방향 $10.2 \mathrm{~km}$, 남북방향 $10.0 \mathrm{~km}$ 의 해역으로 설정하여 맹방 해수욕장과 덕산 해수욕장, 마읍천을 모두 포함하였다. 격자간격은 최소 $15 \mathrm{~m}$, 최대 $45 \mathrm{~m}$ 로 대상영역의 해상도를 최대한 반영하였으며, 이때 격자망은 82,460 개의 격자로 구성하였다(Table 2). Fig. 5에 격자망도와 수 심도를 도시하였고, 초기 수심은 2017년 3월 관측된 자료를 활 용하였다.

Table 2 Operating conditions for numerical simulation

\begin{tabular}{cc}
\hline \hline Domain size & $10.2 \mathrm{~km} \times 10.0 \mathrm{~km}$ \\
Grid size & $\Delta x$ or $\Delta y=15 \mathrm{~m} \sim 45 \mathrm{~m}$ \\
Grid number & $82,460(434 \times 190)$ \\
Computing time & 1 day \\
Offshore boundary & Representative wave specifications \\
\hline
\end{tabular}




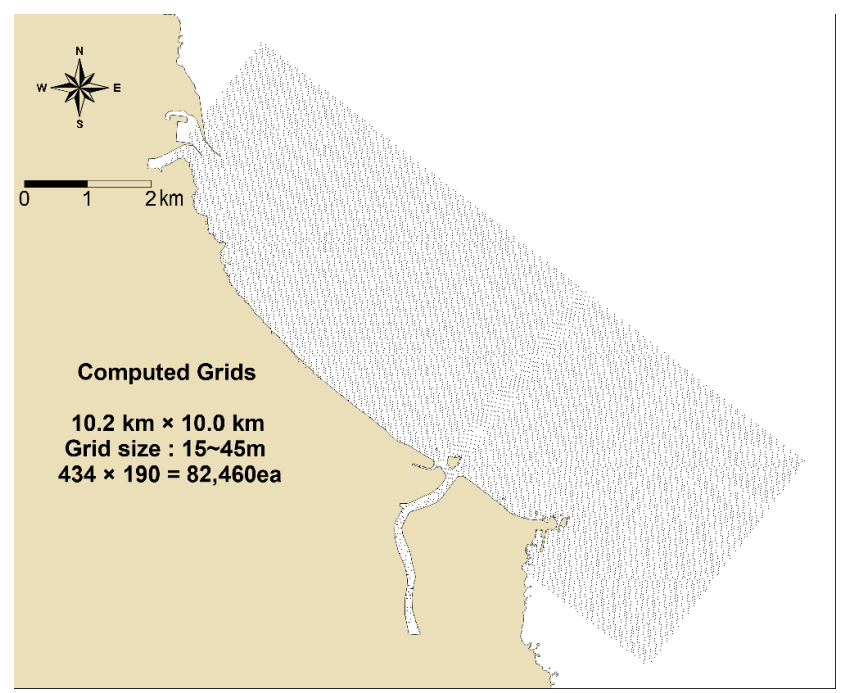

(a) Numerical grid

Fig. 5 numerical grid and bathymetry

\section{3 모델 검증}

3.3.1 파랑 검증

$\mathrm{NOAA}$ 자료를 이용하여 외해 경계조건을 구성한 후, 파랑변 형 실험에 따른 파고의 변화를 비교·검토하였다. 비교 자료는 해안선으로부터 약 $800 \mathrm{~m}$ 이격되어 약 $31.5 \mathrm{~m}$ 수심 저면에 설치 된 초음파식 기기로부터 2017년 3월 1일부터 2019년 1월 26일 까지 약 23개월간 수집된 파랑 관측 자료를 이용하였다.

Fig. 6은 동기간의 관측자료와 수치결과에 대한 시계열을 비 교한 결과이며, 관측치의 고파랑에 비해 수치결과의 파고가 다 소 낮게 계산되었다. 이 결과는 NOAA WaveWatchIII 격자 간격 이 $0.5^{\circ}$ 로써 수심 및 지형의 해상도가 낮게 재현되어, 모델 입력 자료로 구성한 $\mathrm{NOAA}$ 의 파고 자료가 낮게 산출된 결과로 판단 된다. 오차 분석 결과 $\mathrm{Bias}$ 는 $0.05, \mathrm{RMSE}$ (Root mean square error)는 0.23 으로 산출되어, 진폭 및 위상 예측결과가 비교적 유 사한 것으로 사료된다.

\subsection{2 대표 파랑 및 가중치}

2017년 3월부터 2019년 1월까지 약 23개월 내습한 파랑에 대 해 각 대표 파랑 등급 별 퇴적물 이동 실험 결과에 미치는 가중 치를 산정하였다. 가중치는 전술한 퇴적물 이동 실험 결과가 1 일(24시간) 기준이므로, 각 파랑이 3 시간 간격임을 고려하여 각

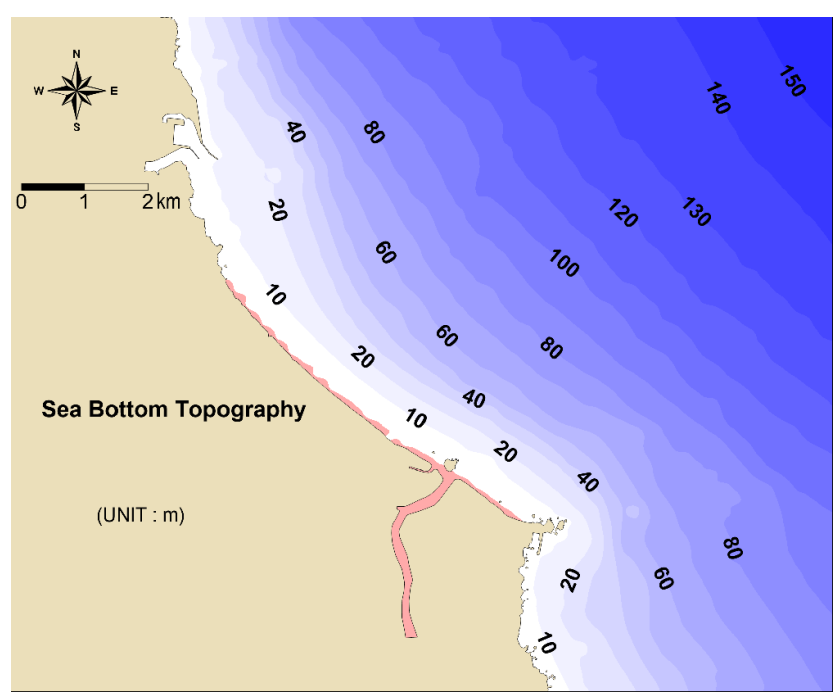

(b) Bathymetry

대표 파랑 등급별 파랑수를 8시간으로 나눠 산정하였고 Table 3 에 제시된 바와 같다. 이 때 전체 파랑 수 5,617개 중 대상지에 내습할 가능성이 낮은 파향 각도를 고려하여, $-40^{\circ} \sim 180^{\circ}$ 이외 의 구간에 존재하는 파랑은 제외하여 검토하였고, 제외된 파랑 수는 230개이다.

\subsection{3 침 - 퇴적량}

각 대표 파랑별 퇴적물 이동 결과에 대표 파랑별 가중치를 적 용하여 산정한 침·퇴적 결과 및 표사 이동량을 Fig 7 과 Fig 8 에 도시하였다. 관측치의 경우 퇴적구간의 등고선 윤곽실선을 없애고 불투명도를 $50 \%$ 로 하여 도시하였고, 수치결과의 경우 퇴적구간의 등고선 윤곽실선을 적용하고 불투명도를 $100 \%$ 로 하여 중첩한 후 도시하였다. 2017년 3월과 2019년 1월 관측된 수심 변화결과로부터, 북측의 맹방 해수욕장과 남측의 덕산 해 수욕장 모두 연안을 따라 $300 \mathrm{~m} \sim 400 \mathrm{~m}$ 의 구간마다 침식과 퇴 적이 반복되는 양상을 나타내고 있다. 수치실험 결과를 관측치 와 중첩하여 비교한 결과, 해안선으로부터 $500 \mathrm{~m}$ 이상 이격된 깊은 수심에서 나타난 관측치의 침 - 퇴적 양상은 수치결과에서 는 나타나지 않고 있다. 그러나 연안을 따른 침·퇴적 양상 및 크기, 위치 등이 유사한 것으로 나타나, 가중치를 적용한 침 퇴적 실험 결과는 만족할 만한 것으로 판단된다.

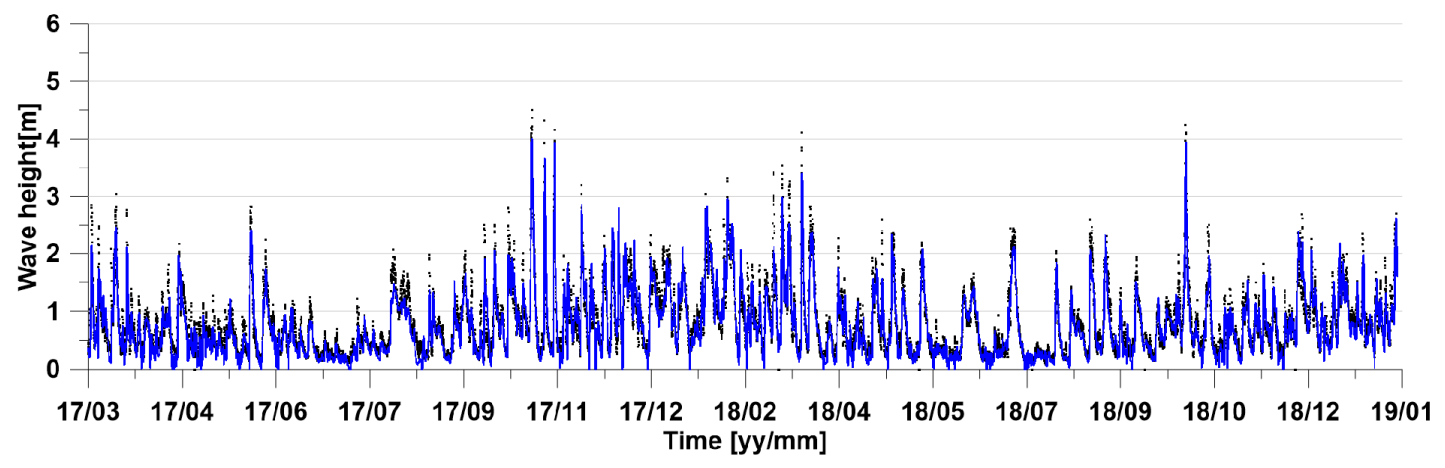

Fig. 6 Comparison of numerical results with observation data $(0$ : Obs. ; - : Num.) 
Table 3 Wave number and weighting factor of Representative wave specifications

\begin{tabular}{|c|c|c|c|c|c|}
\hline Order & Wave number & Weighting factor & Order & Wave number & Weighting factor \\
\hline 1 & 505 & 63.13 & 32 & 2 & 0.25 \\
\hline 2 & 534 & 66.75 & 33 & 4 & 0.50 \\
\hline 3 & 432 & 54.00 & 34 & 0 & 0.00 \\
\hline 4 & 572 & 71.50 & 35 & 5 & 0.63 \\
\hline 5 & 276 & 34.50 & 36 & 0 & 0.00 \\
\hline 6 & 312 & 39.00 & 37 & 1 & 0.13 \\
\hline 7 & 287 & 35.88 & 38 & 0 & 0.00 \\
\hline 8 & 198 & 24.75 & 39 & 0 & 0.00 \\
\hline 9 & 221 & 27.63 & 40 & 0 & 0.00 \\
\hline 10 & 299 & 37.38 & 41 & 2 & 0.25 \\
\hline 11 & 260 & 32.50 & 42 & 0 & 0.00 \\
\hline 12 & 186 & 23.25 & 43 & 0 & 0.00 \\
\hline 13 & 122 & 15.25 & 44 & 0 & 0.00 \\
\hline 14 & 187 & 23.38 & 45 & 0 & 0.00 \\
\hline 15 & 135 & 16.88 & 46 & 0 & 0.00 \\
\hline 16 & 162 & 20.25 & 47 & 0 & 0.00 \\
\hline 17 & 161 & 20.13 & 48 & 0 & 0.00 \\
\hline 18 & 115 & 14.38 & 49 & 0 & 0.00 \\
\hline 19 & 78 & 9.75 & 50 & 0 & 0.00 \\
\hline 20 & 62 & 7.75 & 51 & 0 & 0.00 \\
\hline 21 & 59 & 7.38 & 52 & 0 & 0.00 \\
\hline 22 & 20 & 2.50 & 53 & 0 & 0.00 \\
\hline 23 & 42 & 5.25 & 54 & 0 & 0.00 \\
\hline 24 & 37 & 4.63 & 55 & 0 & 0.00 \\
\hline 25 & 12 & 1.50 & 56 & 0 & 0.00 \\
\hline 26 & 29 & 3.63 & 57 & 0 & 0.00 \\
\hline 27 & 19 & 2.38 & 58 & 0 & 0.00 \\
\hline 28 & 10 & 1.25 & 59 & 0 & 0.00 \\
\hline 29 & 28 & 3.50 & 60 & 0 & 0.00 \\
\hline 30 & 6 & 0.75 & 61 & 0 & 0.00 \\
\hline 31 & 7 & 0.88 & 62 & 0 & 0.00 \\
\hline
\end{tabular}

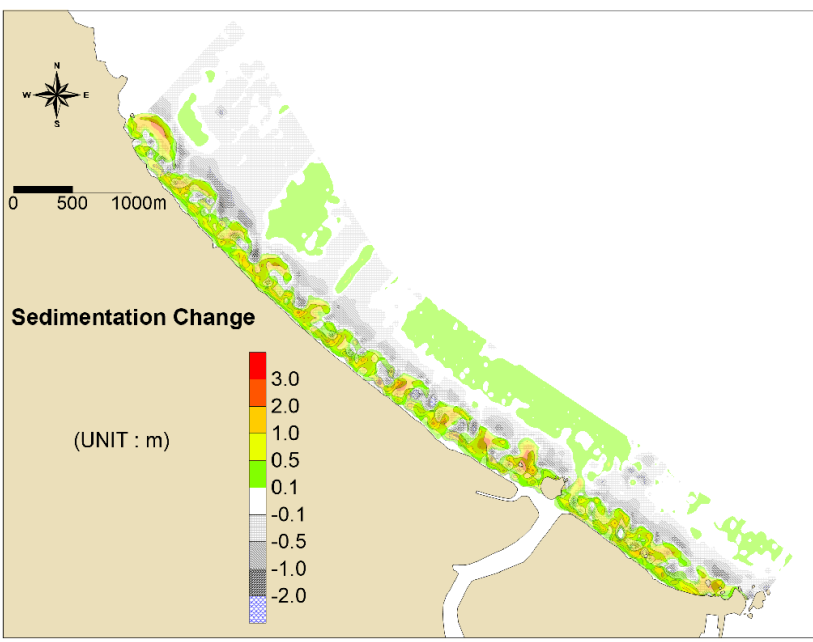

Fig. 7 Comparison of bathymetry change between observation data and numerical result (2017. $03 \sim 2019$. 01)

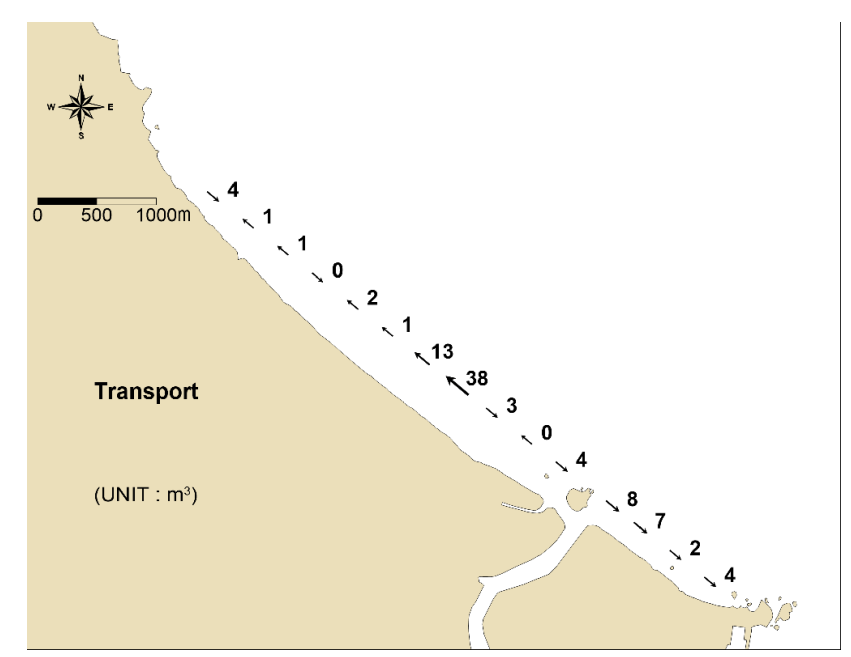

Fig. 8 Sediment budget transport result (2017. $03 \sim 2019.01)$ 
표사 이동량을 산정한 결과, 덕산 해수욕장의 경우 $10 \mathrm{~m}^{3} / \mathrm{day}$ 이하의 표사량이 연안을 따라 남측으로 이동하는 경향을 보이 고 있다. 맹방 해수욕장의 경우 마읍천으로부터 약 $1.3 \mathrm{~km}$ 북측 해안 인근에서 국지적으로 많은 표사가 북으로 이송되는 양상 을 나타내고 있다. 그러나 마읍천 북측의 맹방 해수욕장 전체를 고려할 때, 표사는 연안을 따라 남과 북으로 이송되는 양상이 혼재된 것으로 판단된다.

\section{4 파랑 변화에 따른 표사환경의 변동 경향 분석}

3.4.1 파랑 변화 분석

파랑 변화에 따른 표사환경의 변동 경향을 분석하기 위하여, $\mathrm{NOAA}$ 의 파랑 자료를 활용하였다. 전체 파랑 자료를 앞서 생성 한 62 개의 대표 파랑 등급별로 분류한 후, 각 등급별 매년 파랑 개수의 추세를 분석하였다. 다음은 그 중 대표 파랑의 추세가
감소하는 경우(대표 파랑 3)와 증가하는 경우(대표 파랑 11) 및 거의 일정한 경우(대표 파랑 9)에 대한 결과를 Fig. 9에 도시하 였다.

전술한 파랑 변화 분석 자료를 이용하여, 2100 년경에 예상되 는 대표 파랑의 개수를 검토하였고, 2018년을 비교 대상으로 하 여, 2018년 대비 2100년의 파랑 변화 추이를 Fig. 10에 도시하였 다. 대표 파랑 1 의 경우 2018년 292개에서 2100년 126개로 약 $57 \%$ 가 감소하였고, 대표 파랑 4의 경우 2018년 230개에서 2100 년 471개로 약 $100 \%$ 증가한 모습을 보이고 있다. 파향-파고별 파랑 변화 추이(Fig. 11)를 살펴보면, 파향 $20^{\circ} \sim 100^{\circ}$, 파고 $2 \mathrm{~m}$ 이하의 파랑은 감소하는 반면, $2 \mathrm{~m}$ 이상의 파랑은 증가하는 것 으로 나타났다. 또한 파고 $3 \sim 4 \mathrm{~m}$ 의 파랑은 $0^{\circ}$ 이하의 북측계열 은 증가한 반면, $100^{\circ}$ 이상의 남측계열에서는 감소하는 추세로 검토되었다.

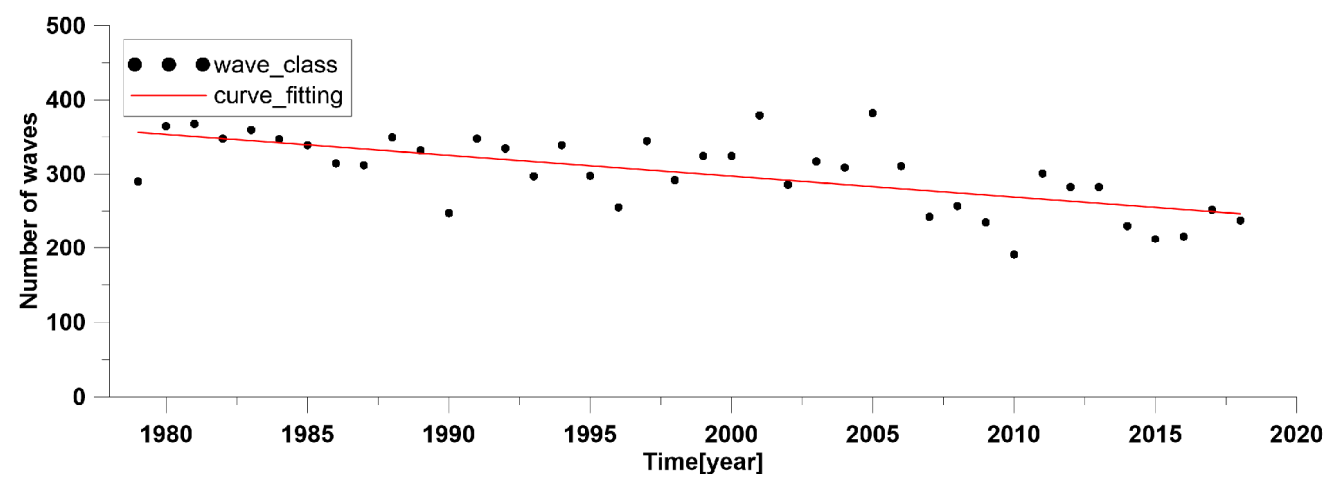

(a) Representative wave number 3

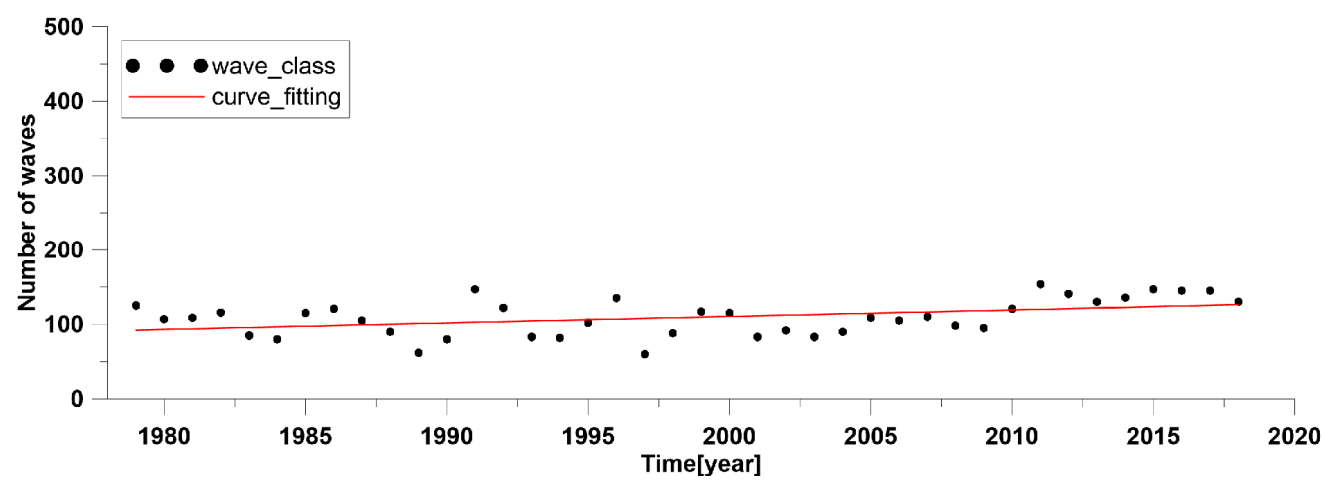

(b) Representative wave number 11

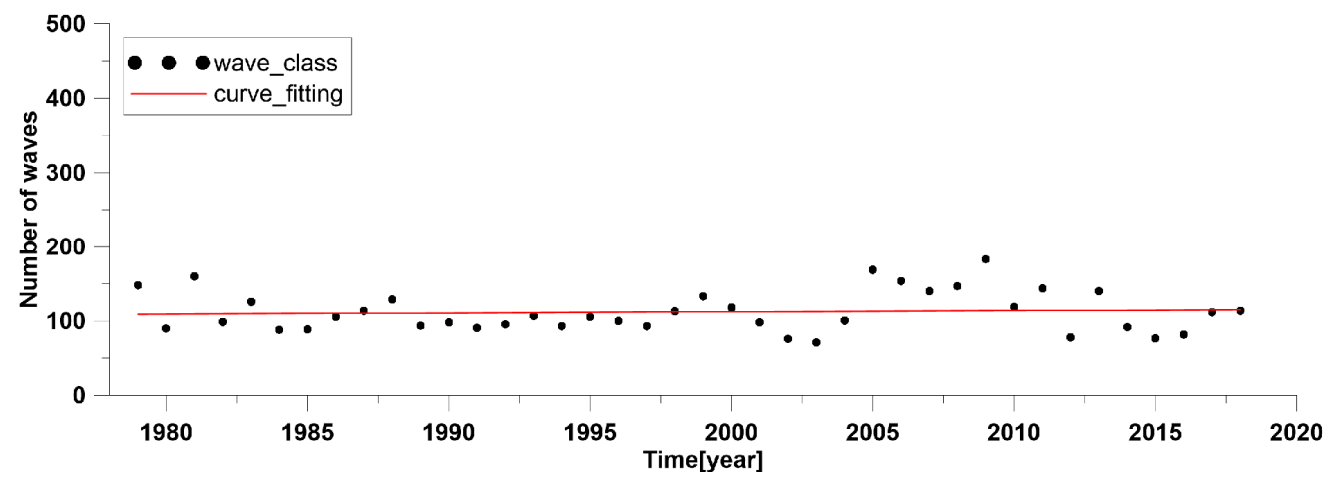

(c) Representative wave number 9

Fig. 9 Annual wave number changes 


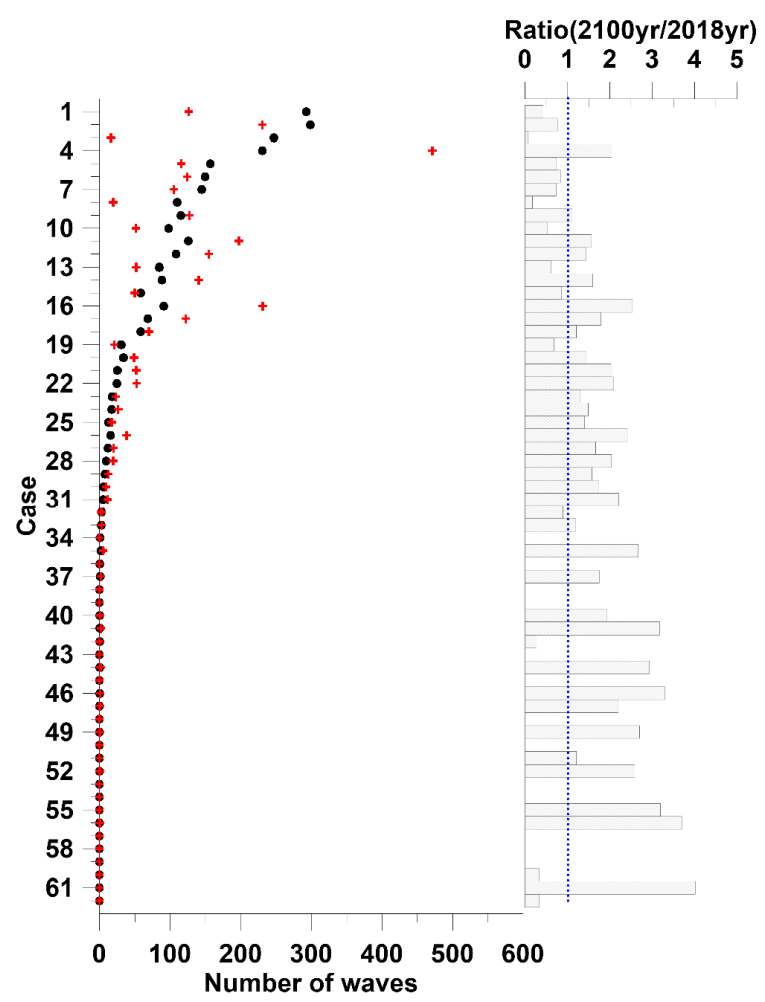

Fig. 10 Change rate of representative wave of 2100 year (black circle : 2018 year ; red cross : 2100 year)

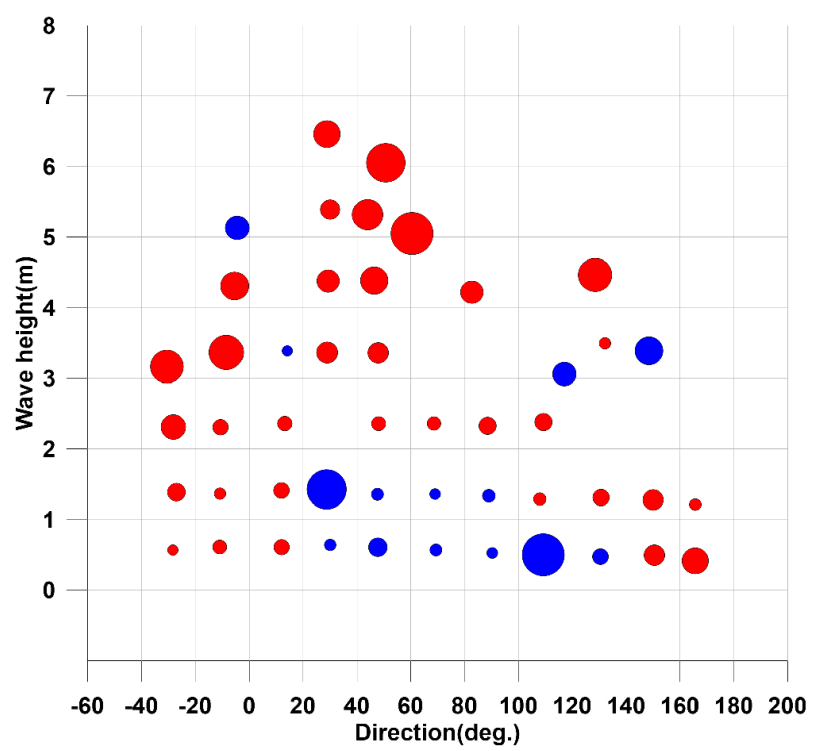

Fig. 11 Change rate bubble plot of representative wave of 2100 year (blue circle : minus ; red circle : plus)

\section{4 .2 표사 환경의 변화 검토}

대표 파랑의 연간 추이를 고려한 가중치를 적용하여, 최종 침 · 퇴적 결과를 산정하였다. 2100년 환경하의 동일기간(2099.03 2101.01)에 대한 수치 실험 결과를 현재 상태(2017.03 2019.01)와 비교하여 Fig. 12에 도시하였다.

파랑 변화를 고려한 수치실험 결과, 연안을 따라 침식과 퇴적 이 반복되는 양상은 등고선으로 확인할 수 있다. 이는 맹방 해수

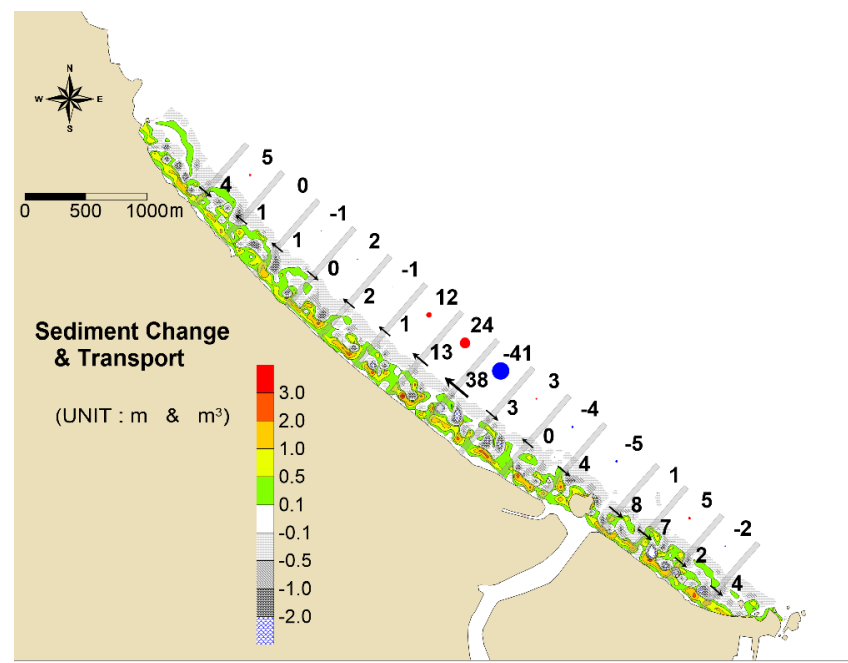

(a) $2017.03 \sim 2019.01$

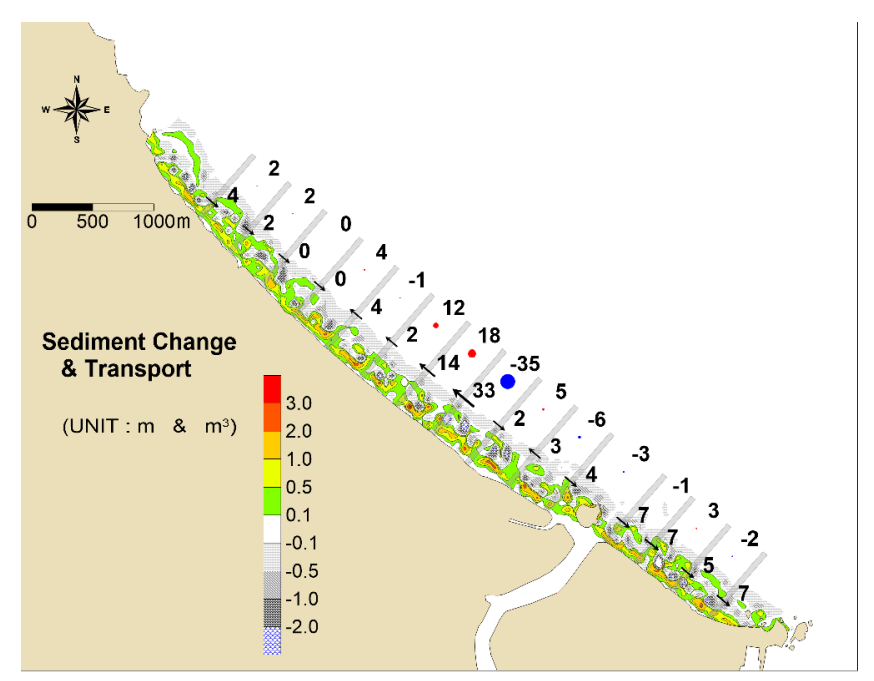

(b) $2099.03 \sim 2101.01$

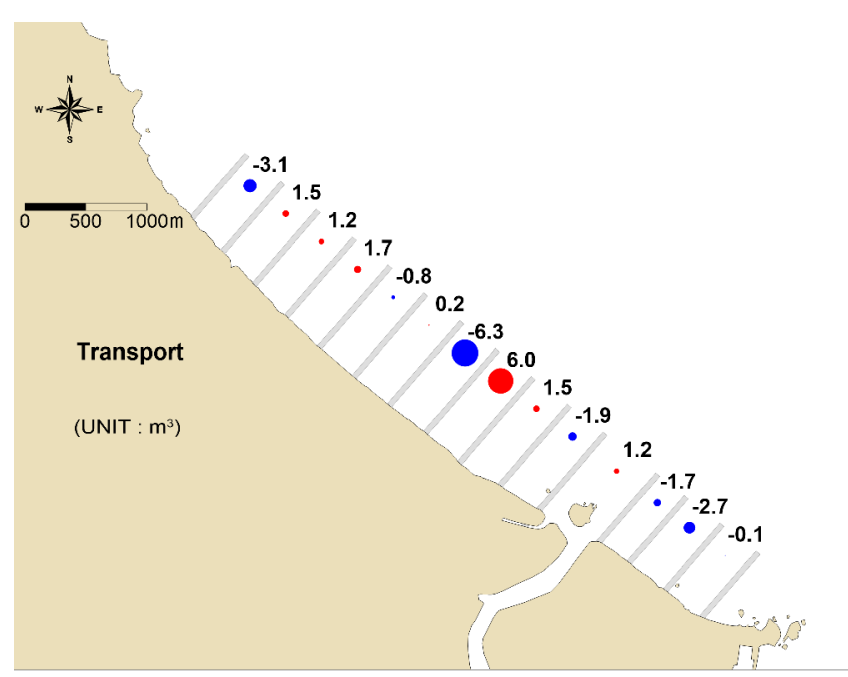

(c) Comparison of sediment budget (2099.03 $2101.01-2017.03 \sim 2019.01)$

Fig. 12 Numerical result of sedimetation changes and sediment budget transport 
욕장을 비롯하여 덕산해수욕장까지 계속되고 있어, 현재의 수치 결과와 비교하여 큰 차이를 나타내지 않는 것으로 판단된다.

구간별 표사 이동량과 함께 구간별 순 표사량을 함께 나타내 었고, 구간별 북측과 남측 경계로 이동하는 표사량을 계산하여 표사량이 증가한 경우 빨간 원으로, 감소한 경우 파란 원으로 값과 함께 도시하였다(Fig. 12(a), (b)). 표사 이동량을 산정한 결 과, 현재상태와 유사하게 덕산 해수욕장의 표사량이 연안을 따 라 남측으로 이동하는 경향을 보이고 있다. 그리고 맹방 해수욕 장의 해안 인근에서 국지적으로 많은 표사가 북으로 이송되는 양상과 함께 마읍천 북측의 해수욕장 전체에서 표사는 연안을 따라 남과 북으로 이동하는 양상이 혼재하는 것으로 나타났다. 또한 현재상태에 국지적인 표사 이동량을 보인 마읍천 북측 $1.3 \mathrm{~km}$ 구간의 순 표사량 변화는, 파랑 변화가 발생한 경우 조금 둔화된 모습을 보이고 있으며, 구간에 따라 남하하는 표사 이동 량이 국지적으로 증가하는 곳이 나타나고 있다. 현재 상태 (2017.03 2019.01)와 비교하여 2100년 환경하의 동일기간 (2099.03 2101.01) 표사량 차이를 각 구간별로 Fig. 12(c)에 도 시하였다. 덕산해수욕장의 북측구간에서 표사량이 다소 감소하 고 있고, 국지적 표사 이동량을 보인 맹방해수욕장 일부 구간에 서 약 $6 \mathrm{~m}^{3}$ 의 표사량 증가와 감소 구간이 이웃하고 있다. 또한 맹방해수욕장 북측구간은 끝단을 제외하고 표사량이 다소 증가 하는 결과를 나타내고 있다. 그러나 전체적인 구역별 순 표사량 과 표사 이동량에서 큰 차이는 발생하지 않는 것으로 판단된다.

\section{4. 결 론}

본 연구에서는 장기간의 파랑과 기상 변화에 의한 모래의 이 동 양상을 검토하기 위해, 동해 맹방 해수욕장을 대상으로 퇴적 물 이동 실험을 수행하고 표사 이동량을 산정하고자 하였다.

파랑을 고려한 퇴적물 이동 실험을 수행하기 위해, 1979년부 터 약 40년간의 NOAA 파랑 자료를 수집하였다. 퇴적물이동 실 험은 초기 수심을 설정하고, 수집된 파랑 시계열 자료를 이용하 여 입력조건을 구성하여, 퇴적물이동 실험을 실시하는 것이 정 석이나, 이처럼 장기간의 수치모의를 수행하기 위해서는 막대 한 계산 시간이 소요될 것으로 판단된다. 따라서 본 연구에서는 40년 간의 파랑자료를 입력 감소 기법(Input reduction tool)을 이 용하여 $1 \mathrm{~m}$ 간격의 파고와 20 도 간격의 파향으로 구분된 62 개의 대표 파랑을 생성하여 전체 파랑을 대변하였다.

모델의 적정성 검토를 위해 2017년 3월부터 2019년 1월까지 $\mathrm{NOAA}$ 파랑 시계열을 입력조건으로 파랑변형 실험을 실시하였 다. 동기간 맹방 해수욕장 전면의 파랑 관측자료와 비교한 결 과, 관측치의 고파랑에 비해 수치결과의 파고가 다소 낮게 계산 되었는데, 이는 NOAA WaveWatchIII 격자의 해상도가 낮아 발 생한 결과로 판단된다. 그러나 오차분석결과 Bias는 $0.05, \mathrm{RMSE}$ 는 0.23 으로 나타나 수치결과에 의한 파랑 예측결과는 만족할 만한 수준으로 사료된다. 또한 동기간 관측된 수심 변화자료를 검증하기 위해, 전술한 대표 파랑에 의한 퇴적물이동 실험을 수 행하였다. 실험 결과 연안을 따른 침 - 퇴적 양상 및 크기와 위 치 등이 관측결과와 유사한 것으로 나타나, 대표 파랑을 이용한 수치 모의 결과는 타당한 것으로 판단된다.
장기간의 파랑 변화에 의한 연안표사 수지 평가를 위해, $\mathrm{NOAA}$ 전체 자료 중 대표 파랑별 연간추이를 분석하여 가중치 를 산정하였다. 가중치가 적용된 2100년 환경의 퇴적물이동 실 험 결과, 현재상태와 비교하여 침 - 퇴적 양상은 큰 변화가 발생 하지 않는 것으로 나타났으며, 현재 상태에서 보인 국지적인 표 사 이동량이 다소 둔화된 모습을 보이고 있다. 그리고 구간에 따라 남하하는 표사 이동량이 국지적으로 증가하는 곳이 나타 나고 있으나, 전체적인 구역별 순 표사량 및 표사 이동량에서는 큰 차이가 발생하지 않는 것으로 나타났다. 이와 같은 결과는 장기간의 파랑 변화가 $\mathrm{NOAA}$ 자료에 의해 각 대표파랑의 연간 추이만을 반영한 것으로, 해수면 상승 및 풍속, 풍향의 변화 등 을 고려한 기후 변화를 반영 시 표사 이동량 및 경향이 더 뚜렷 해질 것으로 예상된다. 본 연구의 장기간 파랑 변화에 의한 모 래의 이동 양상 결과를 통해 동해안의 연안 표사 수지 평가와 관리체계 수립의 기초자료로 활용될 수 있을 것으로 판단된다.

\section{후 기}

본 연구는 2019년 해양수산부 재원으로 해양수산과학기술진 흥원의 지원을 받아 수행된 연구결과 중 일부임을 밝히며, 연구 비 지원에 감사드립니다.

\section{References}

Deltares, 2017. Description_and_User_Manual_Input_Reduction_Tool. Deltares, 2018a. Delft3D-FLOW User Manual.

Deltares, 2018b. Delft3D-WAVE User Manual.

Kim, D.S., Lee, G.R., 2015. Seasonal Changes of Shorelines and Beaches on East Sea Coast, South Korea. Journal of the Korean Geographical Society, 50(2), 147-164.

Kim, M.J., Son, D.H., Yoo, J.S., 2018. Analysis of Seasonal Morphodynamic Patterns using Delft3D in Anmok Coast. Journal of Coastal Disaster Prevention, 5(4), 183-192. http://doi.org/10.20481/kscdp.2018.5.4.183

Ministry of Oceans and Fisheries, 2019. Coast Erosion Status. [Online] Available at: <http://coast.mof.go.kr/coastErosion/ status/erosionLoad1.do $>$ [Accessed October 2019].

NOAA/ National Weather Service, 2019. NWW3 Data Access. [Online] Available at: <https://polar.ncep.noaa.gov/waves/ download.shtml $>$ [Accessed October 2019].

Van Rijn, L.C., 2001. General View on Sand Transport by Currents and Waves: Data Analysis and Engineering Modelling for Uniform and Graded Sand (TRANSPOR 2000 and CROSMOR 2000 models). Delft Hydraulics, The Netherlands.

Van Rijn, L.C., Walstra, D.J., Grasmeijer, B.T., Sutherland, J., Pan, S., Sierra, J., 2003. The Predictability of Cross-shore Bed Evolution of Sandy Beaches at the Time Scale of Storms and Seasons using Process-based Profile Models. Coastal Engineering, 47, 295-327. 